2 Nocturnal and diurnal feeding by Galaxias auratus, a lentic

3

4

5

6

7

8

9

10

12

13

14

15

16 Nocturnal and diurnal feeding by Galaxias auratus

17

18

19

20

21

22

23

24

25

Australia

Running Headline:

Keywords:

\section{galaxiid fish}

Stuart-Smith, R.D., Barmuta, L.A., and White, R.W.G.

R.D. Stuart-Smith, ${ }^{1}$ L.A. Barmuta, and R.W.G. White. School of Zoology and Tasmanian

Aquaculture and Fisheries Institute, University of Tasmania, Private Bag 5, Hobart, Tasmania 7001,

${ }^{1}$ Corresponding author (ph: +613 6226 2632, email: rstuarts@utas.edu.au).

Diel feeding, Galaxias auratus, Daily ration, Gastric evacuation 


\section{1}

\section{Extended summary}

1. We examined the diel feeding pattern, gastric evacuation and daily ration of a lentic, threatened Tasmanian galaxiid fish, Galaxias auratus. Analysis of stomach contents and consumption estimates based on collections of fish every $3 \mathrm{~h}$ over three $24-\mathrm{h}$ periods in summer 2002/2003 revealed an unusual pattern where feeding always occurred during both the day and night, with no obvious peaks. No evidence of size-based temporal partitioning of feeding was found, suggesting that this consistent feeding pattern was representative of the population at this time, and not simply a result of different sized fish feeding at different times.

2. We estimated the gastric evacuation rate of G. auratus in a laboratory experiment, using the two most important prey taxa and at the temperatures recorded in the field during fish collections. The emptying of the stomach was best described by an exponential model, with rate parameters $(R)$ of 0.104 and 0.081 for the evacuation of the amphipod, Austrochiltonia australis, and the cladoceran, Daphnia carinata, at water temperatures of $11.5^{\circ} \mathrm{C}$ and $16.5^{\circ} \mathrm{C}$ respectively.

3. Daily ration of $G$. auratus in summer was estimated to be approximately $3 \%$ (dry body weight) using the models of Elliot \& Persson and Eggers, which is similar, but slightly lower than daily ration estimates reported for other similar sized fishes. 


\section{Abstract}

2 We examined the diel feeding pattern, gastric evacuation and daily ration of a lentic,

3 endemic Tasmanian galaxiid fish, Galaxias auratus. Analysis of stomach contents and

4 consumption estimates based on collections of fish every 3 h over three 24 -h periods

5 in summer 2002/2003 revealed that feeding always occurred during both the day and

6 night, with no obvious peaks. We also estimated the gastric evacuation rate of $G$.

7 auratus in a laboratory experiment using the two prey species found to be dominant in

8 stomachs of field sampled fish. The relationship was best described by an exponential

9 model, with rate parameters $(R)$ of 0.104 and 0.081 for the evacuation of the

10 amphipod, Austrochiltonia australis, and the cladoceran, Daphnia carinata, at water

11 temperatures of $11.5^{\circ} \mathrm{C}$ and $16.5^{\circ} \mathrm{C}$ respectively. Daily ration of G. auratus in

12 summer was estimated to be approximately $3 \%$ (dry body weight) using the models of

13 Elliot \& Persson and Eggers. Galaxias auratus appears to be unusual in that its

14 feeding pattern cannot be classified as nocturnal, diurnal or crepuscular, but its gastric

15 evacuation and daily ration estimates are still similar to other comparable Northern

16 Hemisphere freshwater fishes.

17

18

19

20

21

22

23

24

25 


\section{Introduction}

2 Whether they are nocturnal, diurnal or crepuscular, most fishes exhibit a distinct diel

3 pattern in feeding (Fraser et al. 1993; Brännäs \& Alanärä 1997; Fraser \& Metcalfe

4 1997). The potential causes of such patterns are complicated and may include factors

5 such as prey availability (Glova et al. 1987), predation risk (Metcalfe et al. 1999),

6 potential for intra- or interspecific competition (Keast \& Welsh 1968), capabilities of

7 each fish species, (e.g. dependence on vision for locating prey: Forrester et al. 1994;

8 Kreivi et al. 1999), or a range of seasonal effects, (e.g. temperature and day length:

9 Riehle \& Griffith 1993; Fraser et al. 1995). Many of these are also interdependent.

10 Studying the diel feeding pattern of a fish species can thus suggest a lot about its

11 ecology, and provides the foundation for estimating the amount of food it consumes

12 daily.

13

14

15 There are some cases where the feeding of a fish species has both diurnal and

16 nocturnal peaks (e.g. rock bass, Ambloplites rupestris; Keast \& Welsh 1968). For

17 fishes that occur in high densities (or when food is limited) this may be caused by

18 temporal partitioning of feeding: in order to reduce the effects of intraspecific

19 competition, some individuals feed nocturnally and some diurnally (Brännäs \&

20 Alanärä 1997). This partitioning may be size-structured and brought about by social

21 interactions, where only the larger, more dominant individuals feed at the most

22 preferred time of day ('preferred' in terms of the trade-off between optimising

23 foraging efficiency and avoiding predators sensu Lima \& Dill 1990). 
1 Members of the Galaxiidae form an important component of the native freshwater fish

2 fauna in temperate regions of the Southern Hemisphere, yet diel feeding patterns are

3 unknown for most species. The lotic galaxiids of New Zealand have been the best

4 studied in this respect, and many are nocturnal foragers (Glova \& Sagar 1989a,

5 1989b). Galaxias auratus (Johnston) is a lentic Tasmanian galaxiid that it has co-

6 existed with introduced brown trout (Salmo trutta Linnaeus) in Lakes Crescent and

7 Sorell, to which it is endemic, since 1868 and still remains in very high densities.

8 Little is known, however, of its ecology. It is believed that the activity of this species

9 is greater at night, but its diel feeding pattern is unknown (Hardie et al. 2006). We

10 hypothesised that G. auratus would also be a nocturnal forager both because of the

11 prevailing evidence from New Zealand congeners and because the potential selective

12 pressures imposed by brown trout (the major predator of G. auratus) would foster

13 feeding in low light conditions. Thus the primary objective of this study was to

14 examine the diel feeding pattern of this lentic galaxiid. The potential for size-based

15 temporal partitioning of feeding was also examined in relation to the observed feeding 16 patterns.

19 When the diel feeding pattern is known, daily ration (or daily food intake) can be 20 estimated with greatest accuracy (Darnell \& Meierotto 1962; Mann 1978; Madon

21 1998). If samples of stomach contents have been collected in the field and the nature

22 of gastric evacuation is known, daily ration can be estimated using a number of

23 existing models, the most commonly used being those of Elliot \& Persson (1978) and

24 Eggers (1977) (Boisclair \& Marchand 1993; Specziár 2002). Despite the importance

25 of galaxiids in temperate Southern Hemisphere freshwater systems, there are no 
1 published estimates of daily ration for any species. A secondary objective of this

2 study was to use the diel feeding data in conjunction with an estimate of the rate of

3 gastric evacuation to estimate daily ration.

4

\section{Methods}

\section{$6 \quad$ Study species and site}

7 Galaxias auratus is a relatively large galaxiid (max total length (TL) $\sim 240 \mathrm{~mm}$, but

8 more commonly to $140 \mathrm{~mm}$ ), which is endemic to the interconnected Lakes Crescent

9 and Sorell on the Tasmanian Central Plateau (c. $\left.42^{\circ} 5^{\prime} \mathrm{S} ; 147^{\circ} 10^{\prime} \mathrm{E}\right)$. It is an

10 opportunistic feeder, with adults eating a variety of aquatic and terrestrial

11 invertebrates, but most often consuming epibenthic crustaceans and insect larvae and

12 plankton when available (Hardie et al. 2004). Brown trout are also abundant in these

13 lakes, which also contain smaller numbers of rainbow trout (Oncorhynchus mykiss

14 Walbaum), short-finned eel (Anguilla australis Richardson) and common carp

15 (Cyprinus carpio L.). The brown trout prey heavily on G. auratus, although their

16 efficiency appears to have been reduced since the mid 1990s, when both lakes became

17 highly turbid (Uytendaal 2003) and G. auratus presumably became harder to locate

18 and capture (Stuart-Smith et al. 2004).

21 G. auratus is listed as 'rare' under the Tasmanian Threatened Species Protection Act

22 1995, and 'vulnerable' under the national Environment Protection and Biodiversity

23 Conservation Act 1999 due to its restricted distribution, yet within these lakes it

24 occurs in arguably the highest densities of any of Tasmania's lentic galaxiids. 
1 Although Lakes Crescent and Sorell are relatively large $\left(23.1\right.$ and $51.6 \mathrm{~km}^{2}$

2 respectively), they are shallow (2.3 and $3.1 \mathrm{~m}$ average depth, respectively), and there

3 are estimated to be in excess of 2 million and 0.5 million G. auratus in Lakes

4 Crescent and Sorell respectively (A. Uytendaal, unpublished data).

\section{$7 \quad$ Diel feeding patterns}

8 Galaxias auratus were captured using a backpack electrofishing unit (Smith-Root Inc.

9 model 12-B) at 3-h intervals for $24 \mathrm{~h}$. A replicate sample was taken exactly $24 \mathrm{~h}$ from

10 the first. This was done on three occasions over summer $2002-2003$, with two of

11 these from Lake Crescent (11-12 December 2002 and 6-7 February 2003) and one

12 from Lake Sorell (13-14 February 2003). The study was conducted in both Lakes

13 Crescent and Sorell in case the feeding pattern of G. auratus was affected by

14 differences in their own populations, or trout or prey populations between the lakes.

15 On each occasion, a suitable stretch of shoreline consisting of uniform cobble rock

16 habitat was chosen and divided into nine shorter stretches, each to be sampled once in

17 that day. Immediately after capture, the fish were killed by overdosing in benzocaine

18 (300 mg L $\left.{ }^{-1}\right)$, weighed, measured (TL), and preserved in $4 \%$ formalin with their

19 abdominal cavity slit open. The water temperature was measured at the time and place

20 of each sample.

23 Stomachs were dissected from fish and contents were removed. Each prey taxon was

24 identified at least to genus, and the relative proportion of volume made up by each 
1 was estimated. Stomach contents were then dried $\left(60^{\circ} \mathrm{C}>48 \mathrm{~h}\right)$ and weighed (to 0.1

$2 \mathrm{mg}$ ) using a Mettler AE 100 analytical balance. A sub-sample of contents from 40

3 stomachs was ashed $\left(540^{\circ} \mathrm{C}>24 \mathrm{~h}\right)$, and ash-free dry weight (AFDW) was estimated

4 for the remainder of stomach contents using the relationship between AFDW and dry

5 weight (DW) of stomach contents in the sub-sample (linear regression, AFDW =

$\left.60.8324 \times \mathrm{DW}+0.0007, r^{2}=0.99, p<0.001, n=40\right)$. To calculate the DW of whole

7 fish minus their stomach contents, the emptied stomachs were returned to the

8 abdominal cavity of the fish, which were then also dried $\left(60^{\circ} \mathrm{C}>96 \mathrm{~h}\right)$ and weighed.

9 For graphical purposes and use in daily ration estimation, the relative stomach

10 contents weight $\left(F_{t}\right)$ was also calculated for fish captured at each time using equation

11 1:

12

13

$$
F_{t}=\frac{G_{t}}{D_{t} \times 1000}
$$

14

15 where $G_{t}$ is the weight of the stomach contents $(\mathrm{mg} \mathrm{DW})$ and $D_{t}$ is the DW $(\mathrm{g})$ of a

16 fish captured at time $t$.

17

18

19 Stomach contents AFDW were log-transformed in order to homogenise variances and compared between times of day by one-way analysis of covariance (ANCOVA) with $\log _{\mathrm{e}}($ fish DW) as the covariate. The positive relationships between transformed fish weights and stomach contents weights were similar for all times on all days, satisfying the ANCOVA assumption of homogeneity of slopes. Any differences in fish sizes are thus unlikely to effect interpretation of results. Where significant differences across 
1 the 9 samples were identified, Tukey's post-hoc test was used to determine which

2 pairs of times differed. In addition to analysis of the amount of food in the stomach,

3 estimates of consumption during each of the 3-h intervals were also used to determine

4 the diel feeding pattern of G. auratus. These were based on the model of Elliot \&

5 Persson (1978) (equation 2, below).

6

7

8 Trellis plots, as implemented in the lattice package of R (Sarkar 2005), were used to

9 examine whether there was any evidence of size-based temporal partitioning in

10 feeding. On each sample date, the fish were split into six slightly overlapping size

11 classes (i.e. "shingles" sensu Cleveland 1994) with equal numbers of fish in each size

12 class, and $F_{t}$ was plotted against time. Any trends were visualised using a loess

13 smoother. If size-based partitioning occurred, we expected that these plots would

14 show different trends over time for small and large fish.

15

16

17 Epibenthic prey

18 Samples of epibenthic invertebrate prey were also taken with fish samples with the

19 aim of detecting if diel changes in prey positioning resulted in changes in abundance

20 of prey that may be available to the fish at different times of the day, a phenomenon

21 well documented in lotic invertebrates (Cowan \& Peckarsky 1994; McIntosh \&

22 Townsend 1994). Immediately before electrofishing each stretch of shoreline, prey

23 were sampled using a suction sampler, with three randomly located quadrats of 576

$24 \mathrm{~cm}^{2}$ sampled in each stretch. This method samples prey from exposed surfaces of the

25 substrate, so it probably more closely represents prey that were available to the fish 
1 than other sampling methods which sample interstitial and other sub-surface habitats

2 (e.g. cores or grabs). Prey samples were preserved in $80 \%$ ethanol and later identified

3 to a minimum of genus level and enumerated in the laboratory using a dissecting

4 microscope. The densities of the amphipod, Austrochiltonia australis on 6-7 February

52003 were estimated by sub-sampling because of the particularly large numbers of

6 this species. Precision of estimates based on sub-sampling ranged up to $\pm 23 \%$, but for

7 most samples was approximately $\pm 15 \%$.

10 The diet of the fish was very low in diversity, with a single prey taxon forming the

11 bulk of stomach contents on each day (Table 1). Only the amphipod A. australis and

12 the gastropod Austropyrgus sp. were used in analyses as these were the most

13 dominant epibenthic prey found in stomach contents. The densities of each in the

14 environment at each sample time were analysed for correlation with their mean

15 relative proportion in stomach contents of fish at those times. Densities of A. australis

16 on 11-12 December 2002 were log transformed as they differed by more than an order

17 of magnitude between times.

18

19

21 The rates at which prey are evacuated from the stomach of G. auratus were

22 determined under controlled laboratory conditions. Due to the dominance of $A$.

23 australis and Daphnia carinata in the diets of field sampled fish on different days

24 (Table 1), two experiments were conducted, one with each prey species. Water

25 temperature influences the rate of gastric evacuation (Elliot 1972; Dos Santos \& 
1 Jobling 1991; Andersen 1999), so as the purpose of the gastric evacuation

2 experiments was to allow estimation of daily ration on different days, experiments

3 were run at the mean temperatures recorded on the days on which these prey were

4 dominant $\left(11.5^{\circ} \mathrm{C}\right.$ for A. australis and $16.5^{\circ} \mathrm{C}$ for D. carinata). Otherwise, both

5 experiments followed the same protocol.

6

7

8 Fish were captured in Lake Crescent by electrofisher $(n=54$, mean TL $=103 \mathrm{~mm}$, range $84-144 \mathrm{~mm}$ ) and maintained in the laboratory in two large holding tanks (approx. $350 \mathrm{~L}$ ) for a minimum of 2 weeks to allow them to acclimate. At the

11 beginning of a trial, they were placed in individual, food-free tanks (350 x $210 \times 260$

$12 \mathrm{~mm}$ ) for $48 \mathrm{~h}$. A known number of prey was introduced and the fish were allowed to

13 feed for $3 \mathrm{~h}$. Fish were then transferred into new tanks without any prey and the 14 number of remaining prey was counted. The DW of prey consumed by each fish was estimated from linear regression of number and DW of each prey species ( $A$. australis: $\log _{\mathrm{e}}(\mathrm{DW})=-0.9182+1.0362 \log _{\mathrm{e}}($ number $), r^{2}=0.95, p<0.001, n=20 ; D$. carinata: $\log _{\mathrm{e}}(\mathrm{DW})=-1.8949+0.9860 \log _{\mathrm{e}}($ number $\left.), r^{2}=0.93, p<0.001, n=20\right)$.

Fish were killed at each of a series of pre-determined intervals after the feeding period and the fish and remaining stomach contents were dried and weighed separately, following the same procedures and equipment as for the field sampled fish.

Regression analysis was used to identify the best model to describe the evacuation of A. australis and D. carinata from the stomach of G. auratus and for estimation of the rate parameter $R$, which was required for the Elliot \& Persson and Eggers models. We 
1 used non-linear regression, rather than linear regression on transformed variables, so

2 that the best model could be chosen and comparisons could be made based on $r^{2}$ and

3 SE values (Elashoff et al. 1982; Bromley 1994).

4

\section{Daily ration}

7 It is widely reported that the Elliot \& Persson model usually provides accurate

8 estimates of consumption (Hayward 1991; Héroux \& Magnan 1996; Specziár 2002),

9 but it is subject to two major sources of error. The first is that as it is based on

10 differences in mean relative stomach contents weights between sample times, and

11 does not account for variation about these means, or when data are not normally

12 distributed or do not satisfy parametric assumptions. Some researchers have used

13 geometric means or medians rather than arithmetic means because of this (Amundsen

14 \& Klemetsen 1986; Parrish \& Margraf 1990). The second is that there is error

15 associated with the measurement of the gastric evacuation rate $(R)$, which is not

16 accounted for. Many studies have completely neglected this.

19 In our study, estimates of consumption based on the Elliot \& Persson model $\left(C_{i}\right)$ for

20 each 3-h interval were made using the bootstrap method, which allowed the error

21 associated with both $F_{t}$ and $R$ to be estimated (Trudel \& Boisclair 1993). Transformed

$22(\operatorname{arcsine} \sqrt{ }) F_{t}$ values from each time period were sampled 5000 times with

23 replacement and means from each were back-transformed. Each of the 5000 back-

24 transformed means (multiplied by 100 to convert to $\% \mathrm{DW}$ of fish) $\left(F_{t}{ }^{*}\right)$ was then used 25 in the Elliot \& Persson model: 
2

$$
C_{i}^{*}=\frac{\left(F_{(t+1)}{ }^{*}-F_{t}^{*} \mathrm{e}^{-R^{*} t}\right) R^{*} t}{1-\mathrm{e}^{-R^{*} t}}
$$

3

4 where $C_{i}$ is the mean of the $5000 C_{i}^{*}$ estimates the consumption during the interval $i$

5 (always $3 \mathrm{~h}$ in this study) expressed as $\% \mathrm{DW}$ of fish, $F_{t}{ }^{*}$ and $F_{(t+1)}{ }^{*}$ are mean back-

6 transformed relative stomach contents weights (\%) at two successive sampling times,

7 and $R^{*}$ is a bootstrap estimate of the evacuation rate. Values of $R^{*}$ were generated

8 using equation 3 :

9

10

$$
R^{*}=R+\left(\mathrm{SE}_{R} \times \mathrm{RN}\right)
$$

11

12 where $\mathrm{SE}_{R}$ is the standard error of $R$, and $\mathrm{RN}$ is a normally distributed random number

13 with a mean of 0 and a standard deviation of 1 (Trudel \& Boisclair 1993). Values of $R$

14 and $\mathrm{SE}_{R}$ were estimated from the non-linear regressions of gastric evacuation (i.e. of

15 A. australis for 11-12 December 2002, and of D. carinata in calculations for 6-7 and

16 13-14 February 2003). 95\% confidence intervals of bootstrap estimates were

17 calculated using Hall's basic method (Davison \& Hinkley 1997). These analyses were

18 conducted in the package "boot" (Canty \& Ripley 2005) in R version 2.2.0 (R

19 Development Core Team 2005).

22 Daily ration using the Elliot \& Persson model is equal to the sum of $C_{i}$ for each day.

23 The bootstrap method was also employed to estimate daily ration using the Eggers 
1 model $\left(C_{24}\right)$, with re-sampling of transformed $F_{t}$ values (5000 permutations) and

2 combining the back-transformed means (\%) with appropriate $R^{*}$ values in equation 4 :

3

4

5

6

\section{Results}

\section{Diel feeding pattern}

Only four empty stomachs were found in 593 fish sampled, and AFDW of stomach contents were consistently high and variable. Differences in AFDW between times on

17 any of the days sampled were not significant, with the exception of the sample at

$18 \quad 18: 15$ on 6 February 2003 , in which stomach contents weights were significantly

19 lower than samples at 12:15, 15:15, and 00:15, 03:15 and at 09:15 on the following

20 day (ANCOVA: $\left.F_{8,159}=2.153, p=0.034\right)$. Estimates of consumption in each of the

21 time intervals revealed feeding during both day and night, but did differ significantly

22 between some sample times, as indicated by non-overlapping confidence intervals

23 (Fig. 1). The greatest feeding occurred between 15:15 - 18:15 and 00:15 - 03:15 on

24 11-12 December 2002, and 18:15 - 00:15 on 6-7 February 2003. Feeding was more 
1 consistent in Lake Sorell on 13-14 February. There were also periods in which Elliot

$2 \&$ Persson estimates were negative. However, confidence intervals of all of these

3 overlapped zero. These were between 15:15 - 18:15 and 00:15 - 03:15 on 6-7

4 February 2003, and 03:15 - 06:15 on 13-14 February 2003 (Fig. 1).

7 Although feeding occurred during both the day and night, this was not the result of

8 different sized fish feeding at different times, i.e. there was no evidence of any size-

9 based differences or temporal partitioning of feeding. Visual inspection of the trellis

10 plots of relative stomach contents weights from different size classes of fish (Fig. A1)

11 revealed no differences in trends over the day on any of the sampling dates. There

12 were also no significant differences in the size (TL) of fish captured at each time on

13 any day (ANOVA: $11-12$ December: $F_{8,229}=0.641, p=0.743 ; 6-7$ February: $F_{8,160}=$

$14 \quad 1.680, p=0.107 ; 13-14$ February: $\left.F_{8,177}=0.312, p=0.961\right)$.

\section{Epibenthic prey}

18 Austrochiltonia australis dominated both stomach contents and epibenthic prey

19 samples on 11-12 December 2002. There was a strong, positive linear relationship

20 between the proportion of A. australis in stomachs of G. auratus and its densities in

21 environmental samples on this day (Pearson correlation coefficient, $r=0.76$ ), with

22 peaks early in the night and early in the day (Fig. 2). There were no correlations

23 between stomach contents and the densities of Austropyrgus sp. on this day despite

24 the fact that this species increased in proportion in stomach contents late in the day 
1 and late in the night. There were no correlations between stomach contents and the

2 densities of either prey on the 6-7 and 13-14 February 2003 (all $|r|<0.13$ ).

3

4

5

6 The evacuation of both A. australis and D. carinata from the stomach of G. auratus

7 followed a curvilinear decay with time (Fig. 3). A simple exponential model yielded

8 the greatest $r^{2}$ and smallest SE for both prey species (equation 5):

9

10

11

12 where $M_{t}$ is the amount of prey remaining in the stomach at time $t(\mathrm{mg} \mathrm{DW})$ and $M_{0}$ is

13 the initial meal size (mg DW).

14

15

16

17

18

19

20

21

22

23 estimates on other days were more similar. Elliot \& Persson estimates were almost

24 identical for all three days. Although not statistically significant, the highest estimates 
1 were on 11-12 December 2002, despite the water temperature being considerably

2 cooler on this day (mean $11.5^{\circ} \mathrm{C}$ as opposed to mean $16.5^{\circ} \mathrm{C}$ on the other two days).

3

4

\section{Discussion}

6 Both analysis of stomach contents weights and the estimation of consumption using

7 the Elliot \& Persson model show that there were no significant peaks in feeding by $G$.

8 auratus and that they fed rather consistently during both night and day on all the dates

9 sampled and in both lakes. Thus, the hypothesis that they feed primarily at night was

10 not supported by our findings. Feeding appeared to be more consistent throughout the

$1124 \mathrm{hr}$ day in fish sampled from Lake Sorell, but this does not alter the conclusions of

12 the study, with G. auratus still observed feeding during day, night and twilight

13 periods. Although the variability in stomach contents weights was high, this is

14 characteristic of fish feeding (Jenkins \& Green 1977; Grant \& Kott 1999; Hartman

15 2000), and, in the context of other similar studies, these data were remarkably free of

16 the problems emphasised by Amundsen \& Klemetsen (1986): weights of stomach

17 contents were not skewed, nor were there many empty stomachs. Our sample sizes

18 were also comparable to, or larger than most similar studies (e.g. Brodeur \& Pearcy

19 1987; Johnson \& Dropkin 1995; Madon 1998).

22 One of the assumptions of the Elliot \& Persson model is that feeding is continuous

23 during each 3-h interval (Elliot \& Persson 1978). Failure to satisfy this assumption

24 can lead to errors in estimates of consumption and possibly negative estimates during 
1 intervals in which consumption is low and not continuous. By keeping the sampling

2 interval short ( $\leq 3$ h, Elliot \& Persson 1978; Cortés, 1997), and because the diet was

3 "fine-grained" (large numbers of small food particles, Cochran \& Adelman 1982), the

4 likelihood of violating this assumption was minimised. However, this assumption may

$5 \quad$ still be violated when fish are feeding close to satiation (Elliot \& Persson 1978;

6 Cochran \& Adelman 1982; Persson 1983). As there were very few empty stomachs

7 found in G. auratus and stomach contents weights were consistently high, it is

8 possible that they were feeding close to satiation, and therefore, in an inconsistent

9 manner. Elliot \& Persson (1978) experimentally tested the effects of violating this

10 assumption and found that even in extreme cases (a fish feeding for only 20 min every

$113 \mathrm{~h}$ ) their model still provided good estimates of actual consumption when the interval

12 was $3 \mathrm{~h}$, but that when there were differences between estimates and actual

13 consumption, the estimates were normally slightly lower than actual consumption.

14 Thus, even if the assumption of continuous feeding was not satisfied in our study, the

15 resulting estimates are unlikely to differ considerably from the real consumption of $G$.

16 auratus; but if at all, they may be slight underestimates. This may help explain those

17 estimates that were low (some negative but with 95\% CI overlapping zero).

20 Feeding of G. auratus was consistent and was not significantly greater during night,

21 day or twilight periods. Although this pattern has occasionally been seen in other

22 species (e.g. coho salmon, Oncorhynchus kisutch: Ruggerone 1989, and brook charr,

23 Salvelinus fontinalis: Héroux \& Magnan 1996) it is unusual amongst fish (Fraser et al.

24 1993; Fraser \& Metcalfe 1997). Although McIntosh \& Townsend (1995) found that

25 Galaxias vulgaris (the common river galaxias) foraged both nocturnally and diurnally, 
1 most galaxiid species have been reported to be nocturnal foragers (Cadwallader 1975;

2 Glova \& Sagar 1989a, 1989b; McDowall 1990) and there is evidence that activity and

3 movement of this species is also greater at night. Diel surveys of G. auratus in a

4 recently translocated population in a trout-free, clear-water dam (Hardie et al. 2006)

5 have suggested that G. auratus spends more time in the cover of complex habitats

6 such as macrophytes during the day, and then moves about in search of food at night.

7 This was supported by preliminary electrofishing for this study, which indicated that

8 numbers of G. auratus in areas of uniform silt substrate were low throughout the day

9 but increased at night. Interestingly, McIntosh \& Townsend (1995) recorded this type

10 of activity/habitat use pattern for G. vulgaris even though this species also feeds

11 during the day. They found that G. vulgaris spent most of the daylight hours in cover,

12 emerging only to capture prey, but actively moved about in search of food during the 13 night.

16 Although further research is needed to establish whether the proposed diel activity/ 17 habitat use pattern of G. auratus persists in the presence of brown trout, it appears that 18 like G. vulgaris, G. auratus still captures prey during times in which it uses complex 19 habitats. This may be due either to a change in feeding strategy from ambush or sit20 and-wait foraging from the edge of complex habitats during the day, to actively 21 searching for prey at night, or to the ability to search for, and capture prey amongst 22 the complex habitat. The latter may be realistic in habitats such as macrophytes, 23 because the ability to feed at night suggests that this species is capable of locating and 24 capturing prey using non-visual stimuli, which would also be advantageous in habitats 
1 that reduce or break up the visual field. This ability also suggests that the current high

2 turbidity of Lakes Crescent and Sorell may not negatively affect their feeding ability.

3

4

5 Another reason that we hypothesised that G. auratus would show a nocturnal peak in

6 foraging is because the risk of predation by brown trout is also likely to differ during

7 the diel cycle. Brown trout are primarily visual predators; although they are capable of

8 nocturnal foraging, they present the greatest predation threat from dawn through to

9 dusk (Allan 1978; Ringler 1979). Brown trout were introduced into Lakes Crescent

10 and Sorell in 1868 and it is possible that they have provided a selective pressure for $G$.

11 auratus to forage nocturnally. While this study cannot determine whether brown trout

12 influence habitat use by G. auratus, it does appear, however, that threat of predation

13 by brown trout has not resulted in a nocturnally biased feeding pattern by G. auratus.
15

16 Diel patterns in prey availability are also known to influence feeding patterns of

17 fishes, and have been implicated in causing the nocturnal peaks in the feeding of other

18 galaxiids (Glova \& Sagar 1989a, 1989b). Prey availability in our study was

19 consistently high throughout the day and night and we suggest that it did not influence

20 the feeding pattern of G. auratus. The evidence for this includes the presence of very

21 few empty stomachs, very high densities of sampled epibenthic invertebrates (the mean density of A. australis was $13300 \mathrm{~m}^{-2}$ and Austropyrgus sp., $264 \mathrm{~m}^{-2}$ ), and the observation of very large, dense swarms of Daphnia carinata during all fish sampling periods on the 6-7 and 13-14 February 2003. Unfortunately Daphnia carinata were not quantitatively sampled as a part of this study due to the absence of planktonic prey 
1 in the diet of G. auratus in preliminary samples and the added logistical

2 considerations of attempting to quantitatively and efficiently sample an invertebrate

3 with such a patchy distribution.

4

5

6 Feeding during both day and night may be caused by intraspecific interactions. Size is

7 the most commonly recorded determinant of social structure in fishes (Danylchuk \&

8 Tonn 2001; Whiteman \& Cote 2004), and size-based resource partitioning has been

9 reported in other galaxiids (Whitehead et al. 2002; David \& Stoffels 2003). Although

10 we could not test explicitly for differences in feeding patterns of individuals in this

11 study because we did not sample the same individual fish at each time of day, there

12 was no evidence of size-based differences in feeding when we examined the amount

13 of food in the stomach throughout the day in different sized individuals within the

14 range of sizes sampled.

15

16

17 The gastric evacuation rates and daily ration estimates of G. auratus are slightly lower

18 than, but still similar to other similar sized lentic fishes from studies undertaken in the

19 Northern Hemisphere (Persson 1982; Boisclair \& Leggett 1988). Interestingly, even

20 though consumption by G. auratus may be a little less than other planktivorous fish

21 (e.g. dace, Phoxinus eos x P. neogaeus: Trudel \& Boisclair 1993; Gauthier \&

22 Boisclair 1997), adult G. auratus may still consume around 400 Daphnia carinata per

23 day. Daphnia carinata are relatively large zooplankters (up to $6 \mathrm{~mm}$ ), and are

24 probably the dominant algal grazers in Lakes Crescent and Sorell (Uytendaal 2003).

25 Thus the predation pressure exerted by such high densities of G. auratus on $D$. 
1 carinata may possibly have a strong influence on algal biomass in these lakes. There

2 has been a growing number of studies that have demonstrated such abilities of fishes

3 to exert top down control on lower trophic levels through trophic cascades (He \&

4 Wright 1992; Karjalainen et al. 1999; Zambrano et al. 2001). This study has not only

5 provided an unusual example of a fish that feeds throughout both night and day, but

6 has also provided empirical data on the predatory capabilities of a galaxiid fish, which

7 offer insight into their role as predators in Southern Hemisphere freshwater systems.

\section{Acknowledgements}

11 The authors wish to thank Jemina Stuart-Smith, Jed MacDonald, and Sarah Stuart-

12 Smith for help in the field, and Scott Hardie, Adam Uytendaal, and the Carp Team of

13 the Inland Fisheries Service of Tasmania (IFS) for valuable comments on the

14 manuscript and for access to unpublished data. R.D S-S was supported by a

15 Tasmanian Aquaculture and Fisheries Institute Postgraduate Scholarship, and further

16 support was provided by the School of Zoology, University of Tasmania. The

17 research was carried under appropriate permits from the Inland Fisheries Service of

18 Tasmania and with the approval of the University of Tasmania Animal Ethics

19 Committee. The authors also wish to thank two anonymous referees for helpful

20 comments on the original manuscript. 


\section{References}

2 Allan, J.D. 1978. Trout predation and the size composition of stream drift. Limnology

3 and Oceanography 23: 1231-1237.

4

5 Amundsen, P. \& Klemetsen, A. 1986. Within-sample variabilities in stomach contents

6 weight of fish - implications for field studies of consumption rate. In: Simenstad,

7 C.A. \& Cailliet, G.M., ed. Contemporary studies on fish feeding. Dr. W. Junk

8 Publishers, Dordrecht, Netherlands. pp. 307-314.

9

10 Andersen, N.G. 1999. The effects of predator size, temperature, and prey

11 characteristics on gastric evacuation in whiting. Journal of Fish Biology 54: 287-301.

13 Boisclair, D. \& Leggett, W.C. 1988. An in situ experimental evaluation of the Elliot

14 and Persson and Eggers models for estimating fish daily ration. Canadian Journal of

15 Fisheries and Aquatic Sciences 45: 138-145.

16

17 Boisclair, D. \& Marchand, F. 1993. The guts to estimate fish daily ration. Canadian

18 Journal of Fisheries and Aquatic Sciences 50: 1969-1975.

20 Brännäs, E. \& Alanärä, A. 1997. Is diel dualism in feeding activity influenced by

21 competition between individuals? Canadian Journal of Zoology 75: 661-669.

23 Brodeur, R.D. \& Pearcy, W.G. 1987. Diel feeding chronology, gastric evacuation and

24 estimated daily ration of juvenile coho salmon, Oncorhynchus kisutch (Walbaum), in

25 the coastal marine environment. Journal of Fish Biology 31: 465-477. 
2 Bromley, P.J. 1994. The role of gastric evacuation experiments in quantifying the

3 feeding rates of predatory fish. Reviews in Fish Biology and Fisheries 4: 36-66.

4

5 Cadwallader, P.L. 1975. Distribution and ecology of the Canterbury mudfish,

6 Neochanna burrowsius (Phillips) (Salmoniformes: Galaxiidae). Journal of the Royal

7 Society of New Zealand 5: 21-30.

8

9 Canty, A. \& Ripley, B. 2005. boot: Bootstrap R (S-Plus) Functions. R package

10 version 1.2-24. R Foundation for Statistical Computing, Vienna, Austria. URL

11 http://www.R-project.org. Accessed 22/12/05.

12

13 Cleveland, W. S. 1994. The elements of graphing data. AT\&T Bell Laboratories, 14 Murray Hill, NJ, U.S.A..

15

16 Cochran, P.A. \& Adelman, I.R. 1982. Seasonal aspects of daily ration and diet of

17 largemouth bass, Micropterus salmoides, with an evaluation of gastric evacuation

18 rates. Environmental Biology of Fishes 7: 265-275.

19

20 Cortés, E. 1997. A critical review of methods of studying fish feeding based on

21 analysis of stomach contents: application to elasmobranch fishes. Canadian Journal of

22 Fisheries and Aquatic Sciences 54: 726-738. 
1 Cowan, C.A. \& Peckarsky, B.L. 1994. Diel feeding and positioning periodicity of a

2 grazing mayfly in a trout stream and a fishless stream. Canadian Journal of Fisheries

3 and Aquatic Sciences 51: 450-459.

4

5 Danylchuk, A.J. \& Tonn, W.M. 2001. Effects of social structure on reproductive

6 activity in male flathead minnows (Pimephales promelas). Behavioural Ecology 12:

$7 \quad 482-489$.

8

9 Darnell, R.M. \& Meierotto, R.R. 1962. Determination of feeding chronology in fishes.

10 Transactions of the American Fisheries Society 91: 313-320.

11

12 David, B.O. \& Stoffels, R.J. 2003. Spatial organisation and behavioural interaction of 13 giant kokopu (Galaxias argenteus) in two stream pools differing in fish density. New

14 Zealand Journal of Marine and Freshwater Research 37: 315-322.

15

16 Davison, A.C. \& Hinkley, D.V. 1997. Bootstrap methods and their application

17 Cambridge University Press: Cambridge.

18

19 Dos Santos, J. \& Jobling, M. 1991. Factors affecting gastric evacuation in cod, Gadus

20 morhua L., fed single-meals of natural prey. Journal of Fish Biology 38: 697-713.

21

22 Eggers, D.M. 1977. Factors in interpreting data obtained by diel sampling of fish

23 stomachs. Journal of the Fisheries Research Board of Canada 34: 290-294. 
1 Eggers, D.M. 1979. Comments on some recent methods for estimating food

2 consumption by fish. Journal of the Fisheries Research Board of Canada 36: 1018-

31020.

4

5 Elashoff, J.D., Reedy, T.J. \& Meyer, J.H. 1982. Analysis of gastric emptying data.

6 Gastroenterology 83: 1306-1312.

7

8 Elliot, J.M. 1972. Rates of gastric evacuation in brown trout, Salmo trutta L.

9 Freshwater Biology 2: 1-18.

10

11 Elliot, J.M. \& Persson, L. 1978. The estimation of daily rates of food consumption for 12 fish. Journal of Animal Ecology 47: 977-991.

13

14 Forrester, G.E., Chace, J.G. \& McCarthy, W. 1994. Diel and density-related changes

15 in food consumption and prey selection by brook char in a New Hampshire stream.

16 Environmental Biology of Fishes 39: 301-311.

17

18 Fraser, N.H.C. \& Metcalfe, N.B. 1997. The costs of becoming nocturnal: feeding

19 efficiency in relation to light intensity in juvenile Atlantic salmon. Functional Ecology

20 11: 385-391.

21

22 Fraser, N.H.C., Metcalfe, N.B. \& Thorpe, J.E. 1993. Temperature-dependent switch

23 between diurnal and nocturnal foraging in salmon. Proceedings of the Royal Society

24 of London (B) 252: 135-139. 
1 Fraser, N.H.C., Heggenes, J., Metcalfe, N.B. \& Thorpe, J.E. 1995. Low summer

2 temperatures cause juvenile Atlantic salmon to become nocturnal. Canadian Journal

3 of Zoology 73: 446-451.

4

5 Gauthier, S. \& Boisclair, D. 1997. The energetic implications of diel onshore-offshore

6 migration by dace (Phoxinus eos x P. neogaeus) in a small oligotrophic lake.

7 Canadian Journal of Fisheries and Aquatic Sciences 54: 1996-2006.

8

9 Glova, G.J. \& Sagar, P.M. 1989a. Feeding in a nocturnally active fish, Galaxias

10 brevipinnis, in a New Zealand stream. Australian Journal of Marine and Freshwater

11 Research 40: 231-240.

12

13 Glova, G.J. \& Sagar, P.M. 1989b. Prey selection by Galaxias vulgaris in the Hawkins

14 River, New Zealand. New Zealand Journal of Marine and Freshwater Research 23:

$15 \quad 153-161$.

16

17 Glova, G.J., Sagar, P.M. \& Docherty, C.R. 1987. Diel feeding periodicity of

18 torrentfish (Cheimarrichthys fosteri) in two braided rivers of Canterbury, New

19 Zealand. New Zealand Journal of Marine and Freshwater Research. 21: 555-561.

20

21 Grant, S.M. \& Kott, E. 1999. Variation in field estimates of daily ration in young

22 yellow perch. Journal of Fish Biology 54: 396-403. 
1 Hardie, S.A., Barmuta, L.A. \& White, R.W.G. 2004. Threatened fishes of the world:

2 Galaxias auratus Johnston, 1883 (Galaxiidae). Environmental Biology of Fishes 71:

3126.

4

5 Hardie, S.A., Barmuta, L.A. \& White, R.W.G. 2006. Comparison of day and night

6 fyke netting, electrofishing and snorkelling for monitoring a population of the

7 threatened golden galaxias (Galaxias auratus). Hydrobiologia 560: 145-158.

8

9 Hartman, K.J. 2000. Variability in daily ration estimates of age-0 striped bass in the

10 Chesapeake Bay. Transactions of the American Fisheries Society 129: 1181-1186.

11

12 Hayward, R.S. 1991. Bias associated with using the Eggers model for estimating fish

13 daily ration. Canadian Journal of Fisheries and Aquatic Sciences 48: 1100-1103.

14

15 He, X. \& Wright, R.A. 1992. An experimental study of piscivore-planktivore

16 interactions: population and community responses to predation. Canadian Journal of

17 Fisheries and Aquatic Sciences 49: 1176-1183.

18

19 Héroux, D. \& Magnan, P. 1996. In situ determination of food daily ration in fish:

20 review and field evaluation. Environmental Biology of Fishes 46: 61-74.

21

22 Jenkins, B.W. \& Green, J.M. 1977. A critique of field methodology for determining

23 fish feeding periodicity. Environmental Biology of Fishes 1: 209-214. 
1 Johnson, J.H. \& Dropkin, D.S. 1995. Diel feeding chronology of six fish species in

2 the Juniata River, Pennsylvania. Journal of Freshwater Ecology 10: 11-18.

3

4 Karjalainen, J., Leppä, M., Rahkola, M. \& Tolonen, K. 1999. The role of

5 benthivorous and planktivorous fish in a mesotrophic lake ecosystem. Hydrobiologia

6 408/409: 73-84.

7

8 Keast, A. \& Welsh, L. 1968. Daily feeding periodicities, food uptake rates, and

9 dietary changes with hour of day in some lake fishes. Journal of the Fisheries

10 Research Board of Canada 25: 1133-1144.

11

12 Kreivi, P., Muotka, T., Huusko, A., Mäki-Petäys, A., Huhta, A. \& Meissner, K. 1999.

13 Diel feeding periodicity, daily ration and prey selectivity in juvenile brown trout in a

14 subarctic river. Journal of Fish Biology 55: 553-571.

15

16 Lima, S.L. \& Dill, L.M. 1990. Behavioral decisions made under the risk of predation:

17 a review and prospectus. Canadian Journal of Zoology 68: 619-640.

18

19 Madon, S.P. 1998. Low-effort regression estimation of daily ration in young walleye,

20 Stizostedion vitreum. Canadian Journal of Fisheries and Aquatic Sciences 55: 2058-

212066.

22

23 Mann, K.H. 1978. Estimating the food consumption of fish in nature. In: Gerking,

24 S.D., ed. Ecology of Freshwater Fish Production. Blackwell Scientific Publications,

25 Oxford. pp. 250-273. 
2 McDowall, R.M. 1990. New Zealand freshwater fishes: a natural history and guide.

3 Heinemann Reed, Auckland. 553pp.

4

5 McIntosh, A.R. \& Townsend, C.R. 1994. Interpopulation variation in mayfly anti-

6 predator tactics: differential effects of contrasting predatory fish. Ecology 75: 2078-

72090.

8

9 McIntosh, A.R. \& Townsend, C.R. 1995. Contrasting predation risks presented by

10 introduced brown trout and native common river galaxias in New Zealand streams.

11 Canadian Journal of Fisheries and Aquatic Sciences 52: 1821-1833.

12

13 Metcalfe, N.B., Fraser, N.H.C. \& Burns, M.D. 1999. Food availability and the

14 nocturnal vs. diurnal foraging trade-off in juvenile salmon. Journal of Animal Ecology

$15 \quad 68: 371-381$.

16

17 Parrish, D.L. \& Margraf, F.J. 1990. Gastric evacuation rates of white perch, morone

18 americana, determined from laboratory and field data. Environmental Biology of

19 Fishes 29: 155-158.

20

21 Persson, L. 1982. Rate of food evacuation in roach (Rutilus rutilus) in relation to

22 temperature, and the application of evacuation rate estimates for studies on the rate of

23 food consumption. Freshwater Biology 12: 203-210.

24 
1 Persson, L. 1983. Food consumption and competition between age classes in a perch

2 (Perca fluviatilis) population in a shallow eutrophic lake. Oikos 40: 197-207.

3

4 R Development Core Team 2005. R: A language and environment for statistical

5 computing. Version 2.2.0. R Foundation for Statistical Computing, Vienna, Austria.

$6 \quad$ URL http://www.R-project.org.

7

8 Riehle, M.D. \& Griffith, J.S. 1993. Changes in habitat use and feeding chronology of 9 juvenile rainbow trout (Oncorhynchus mykiss) in fall and the onset of winter in Silver 10 Creek, Idaho. Canadian Journal of Fisheries and Aquatic Sciences 50: 2119-2128.

12 Ringler, N.H. 1979. Selective predation by drift-feeding brown trout (Salmo trutta).

13 Journal of the Fisheries Research Board of Canada 36: 392-403.

14

15 Ruggerone, G.T. 1989. Gastric evacuation rates and daily ration of piscivorous coho 16 salmon, Oncorhynchus kisutch Walbaum. Journal of Fish Biology 34: 451-463.

18 Sarkar, D. 2005. Lattice: Lattice Graphics. R package version 0.12-10.

20 Specziár, A. 2002. An in situ estimate of food consumption of five cyprinid species in 21 Lake Balaton. Journal of Fish Biology 60: 1237-1251.

23 Stuart-Smith, R.D., Richardson, A.M.M. \& White, R.W.G. 2004. Increasing turbidity 24 significantly alters the diet of brown trout: a multi-year longitudinal study. Journal of 25 Fish Biology 65: 376-388. 
2 Trudel, M. \& Boisclair, D. 1993. An in situ evaluation of the day-to day variation in

3 the quantity of food consumed by fish. Canadian Journal of Fisheries and Aquatic

4 Sciences 50: 2157-2165.

5

6 Uytendaal, A. 2003. Water quality in Lakes Sorell and Crescent: underlying

7 processes and management options. Inland Fisheries Service,

8 http://www.ifs.tas.gov.au, 29 October 2003.

9

10 Whitehead, A.L., David, B.O. \& Closs, G.P. 2002. Ontogenetic shift in nocturnal

11 microhabitat selection by giant kokopu in a New Zealand stream. Journal of Fish

12 Biology 61: 1373-1385.

13

14 Whiteman, E.A. \& Cote, I.M. 2004. Dominance hierarchies in group-living cleaning

15 gobies: causes and foraging consequences. Animal Behaviour 67: 239-247.

16

17 Zambrano, L., Scheffer, M. \& Martínez-Ramos, M. 2001. Catastrophic response of

18 lakes to benthivorous fish introduction. Oikos 94: 344-350.

19

20

21

22

23

24 


\section{Figure captions}

2 Fig. 1. Diel patterns in relative stomach contents weights $\left(F_{t}\right.$, left column $)$ and

3 corresponding Elliot \& Persson three-hourly consumption estimates ( $C_{i}$, right column)

4 for Galaxias auratus sampled from Lake Crescent on 11-12 December 2002 (top), 6-7

5 February (middle) and from Lake Sorell on 13-14 February (bottom) 2003. Relative

6 stomach contents weights are plotted as box-and-whisker plots with raw data overlaid

7 as open circles. Consumption estimates are bootstrap estimates of means $+95 \%$

8 confidence intervals. Horizontal black bars represent hours of darkness.
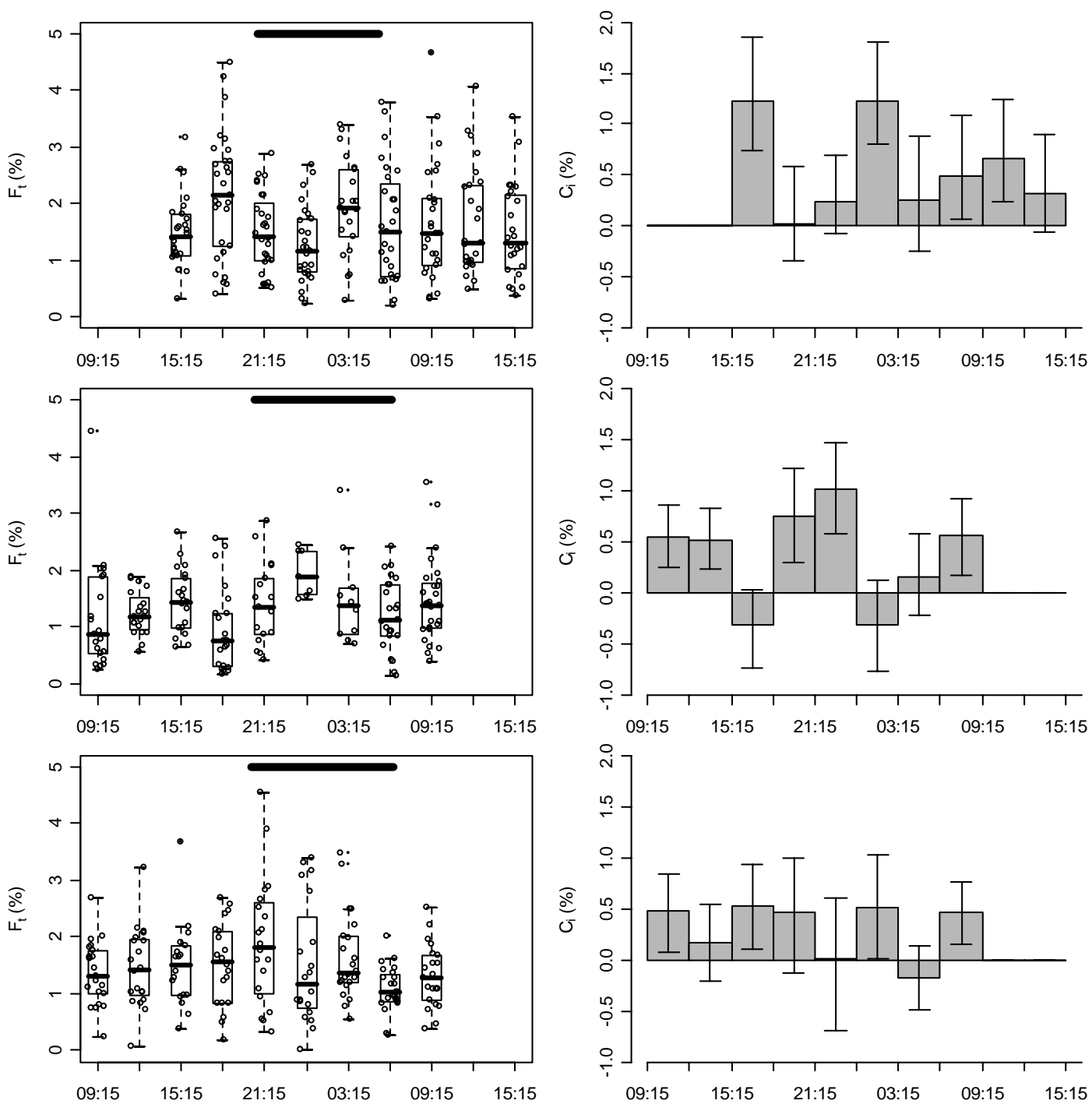
1 Fig. 2. Density of Austrochiltonia australis in samples of epibenthic prey (open

2 circles) and the mean ( \pm SE) proportion by volume of stomach contents made up by

3 this prey in Galaxias auratus (closed circles) on 11-12 December 2002. No significant

4 correlations were found between prey density and stomach contents on any of the

5 other days sampled.

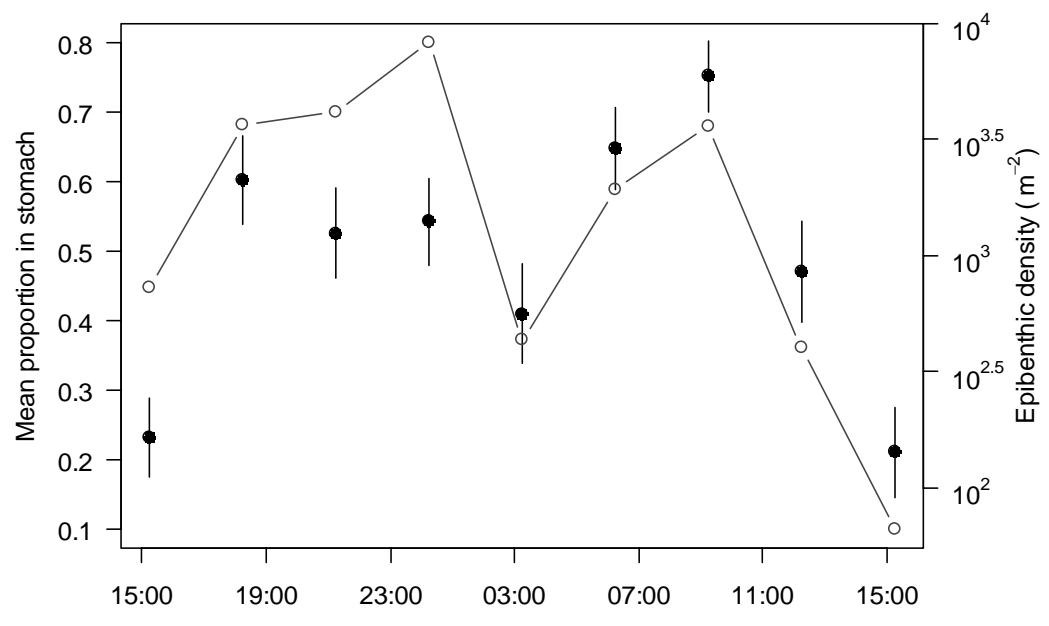

6

7 
1 Fig. 3. Evacuation of Austrochiltonia australis (left) and Daphnia carinata (right)

2 from the stomach of Galaxias auratus at $11.5^{\circ} \mathrm{C}$ and $16.5^{\circ} \mathrm{C}$, respectively. Circles

3 represent the fraction (by DW) of the original meal remaining in the stomach at each

4 time. The rate parameter, $R$ ( \pm its asymptotic standard error), for the evacuation of $A$.

5 australis $=0.1044 \pm 0.0158$ and the $r^{2}=0.8096$. For the evacuation of $D$. carinata, $R$

$6 \quad( \pm$ its asymptotic standard error $)=0.0805 \pm 0.0052$ and $r^{2}=0.8277$

7
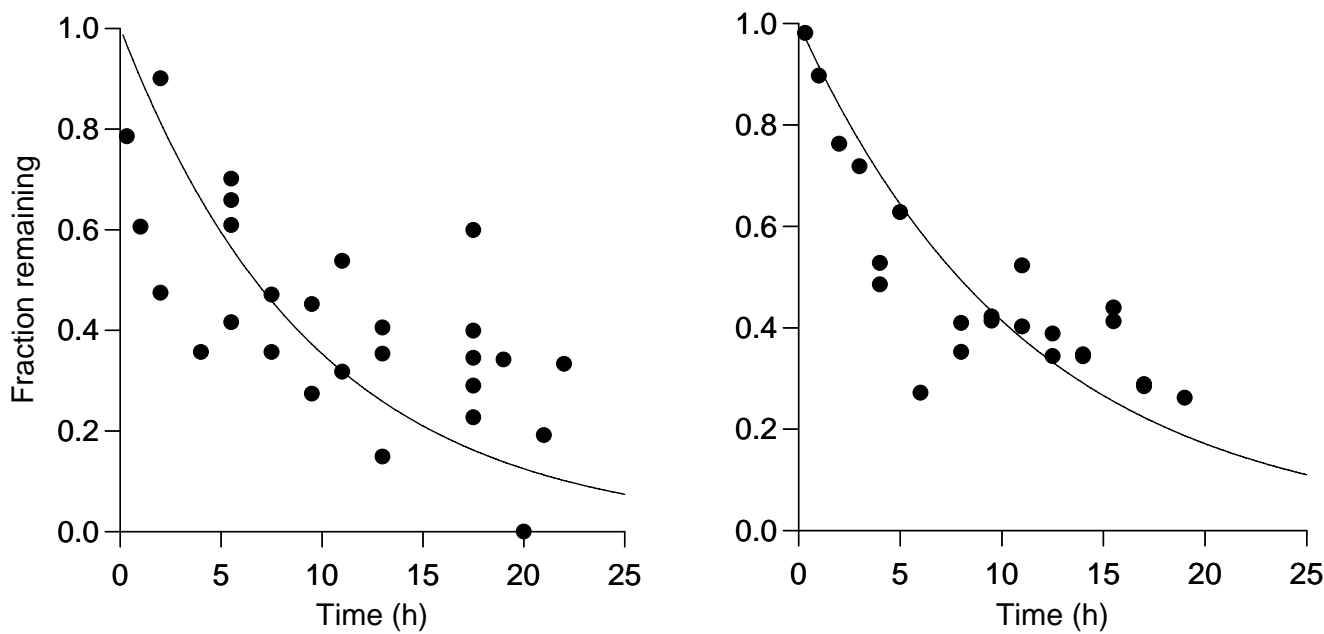

8

9

10 
1 Fig. 4. Daily ration estimates (\%DW) (and 95\% CI) for Galaxias auratus on the three

2 days sampled using the Eggers (1977) model (unshaded bars) and the Elliot \& Persson 3 (1978) model (shaded bars).

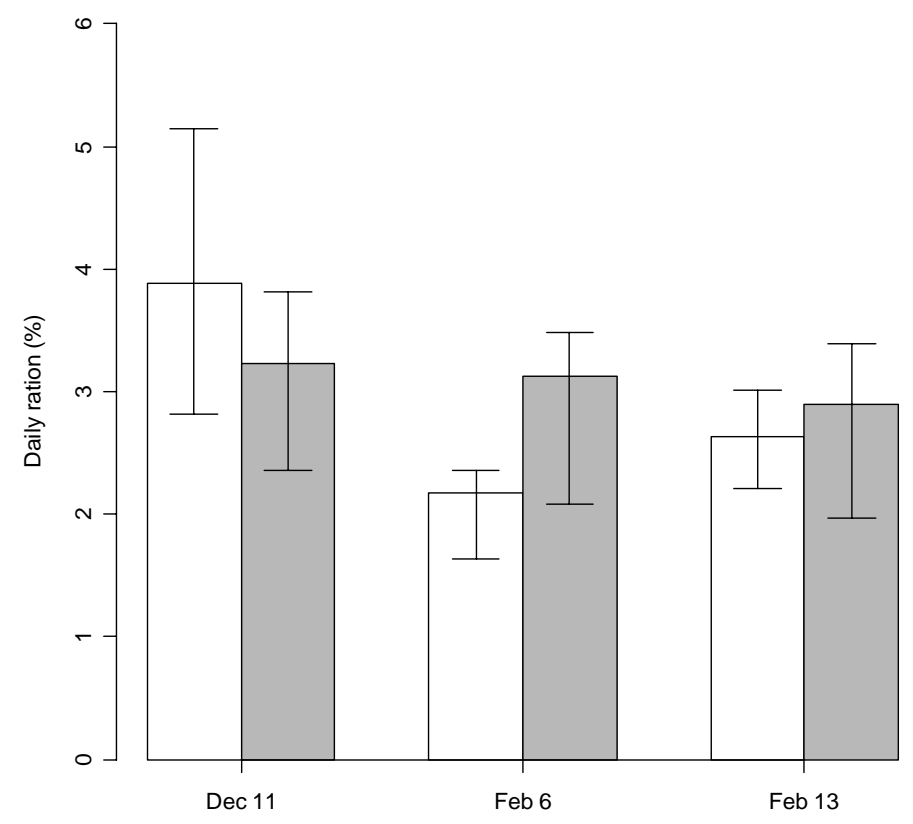

4 


\section{Appendix}
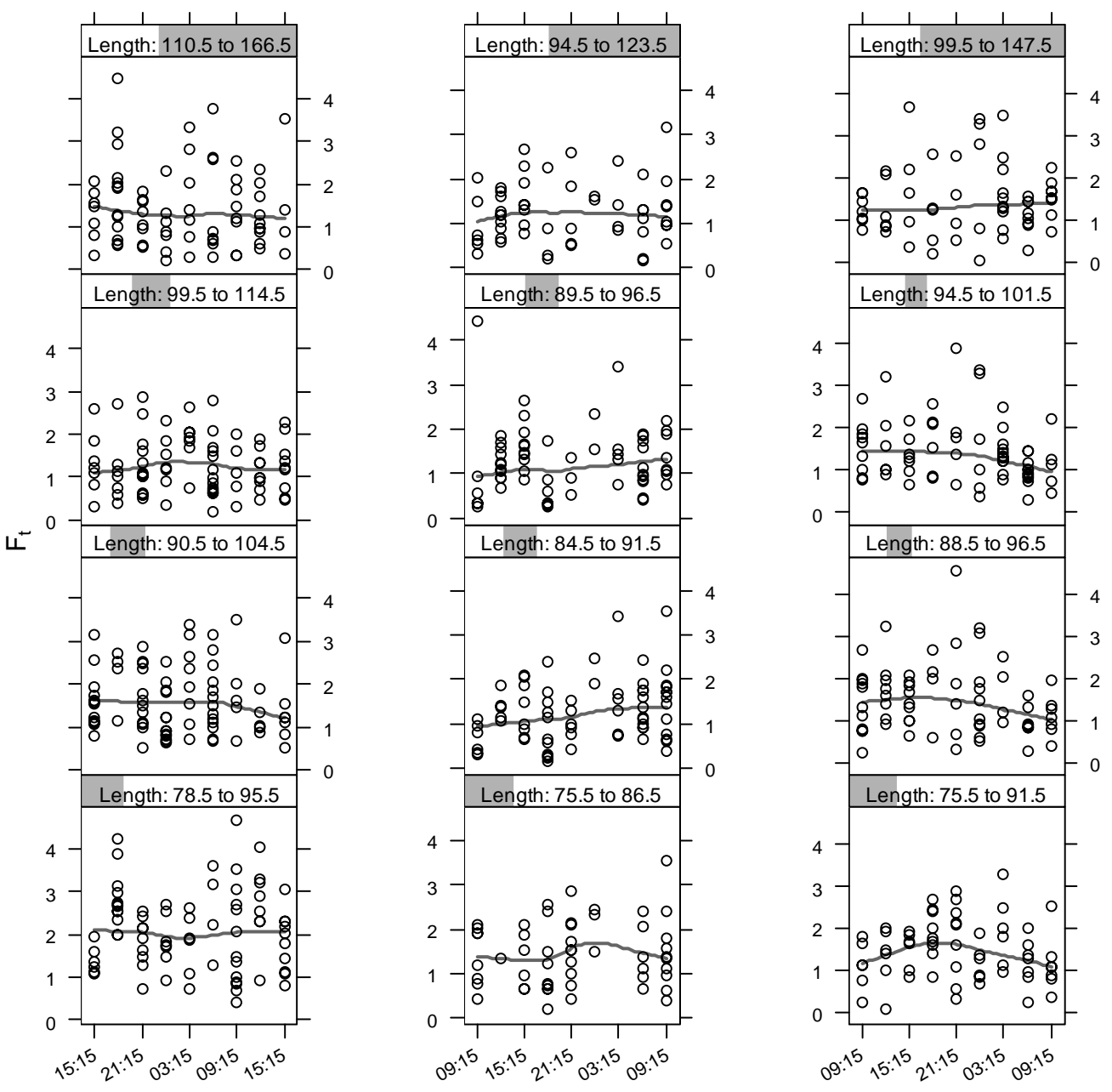

3

4 Fig A1. Trellis plots of relative stomach contents weights $\left(F_{t}\right)$ of different size classes

5 of fish (TL in mm) on 11-12 December 2002 (left column), 6-7 February, 2003

6 (middle column) and 13-14 February 2003 (right column) with a loess smoother

7 superposed (gray line) to assist in visualizing any trends. Each panel has an equal

8 number of fish, and the lengths of the fish included in each panel increase from

9 bottom to top with a slight overlap in the fish included in each panel as indicated by 
1 the sizes specified in each title strip. The shading in the title strip of each panel

2 provides a graphical key to the size range of fish included in each panel.

3 